\title{
CARBONATION OF STEEL SLAG FOR CO SEQUESTRATION: LEACHING OF PRODUCTS AND REACTION MECHANISMS
}

\author{
Wouter J.J. Huijgen ${ }^{1}$ \& Rob N.J. Comans ${ }^{1,2}$ \\ ${ }^{1)}$ Energy Research Centre of The Netherlands, P.O. Box 1, 1755ZG Petten, The \\ Netherlands \\ 2) Department of Soil Quality, Wageningen University, P.O. Box 8005, 6700EC \\ Wageningen, The Netherlands
}

Number of pages: 10

Number of figures: 5

Date: February 23, 2006 


\section{Effect of Grinding}

Grinding the crushed $(<2 \mathrm{~mm})$ fresh steel slag sample 0-c increases the specific surface area by an order of magnitude (Table 1) and increases the leaching of Co by 1-2 orders of magnitude, of $\mathrm{Cr}$ by 1 order of magnitude $($ at $\mathrm{pH}<6)$ and of $\mathrm{Mn}(\mathrm{pH}<$ 8), $\mathrm{Pb}(\mathrm{pH}<6)$ and $\mathrm{W}$ by less than 1 order of magnitude (Figure S5). The increase in the amount of tungsten and cobalt leached might be attributed to the tungsten carbide grinding equipment, which may contain traces of Co. For the other elements, grinding does not significantly affect their leaching behavior.

\section{Effect of Prior Leaching in the Autoclave Reactor}

The prior leaching of elements into the water phase during the aqueous steel slag carbonation experiments for preparation of samples 60 and 90 is shown in Figure S3. For both samples, the most mobile elements are $\mathrm{Cl}$ (i.e., 69 and 80\% of its total amount has dissolved for samples 60 and 90, respectively) and $\mathrm{Na}(55 / 45 \%)$. Other soluble elements are the other alkali metals (i.e., K (22/12\%) and Li (19/32\%)), S $(18 / 6 \%)$ and Mo $(16 / 4 \%)$. Of the other elements less than 10 and 3\% of their total amount present has been leached during the carbonation experiments for sample 60 and 90, respectively. Due to the lower liquid to solid ratio applied during preparation

of sample 90 (Table 1), the dissolution of most constituents during the mineral $\mathrm{CO}_{2}$ sequestration experiments is less prominent than for sample 60 . 


\section{Implications of Leaching on the Re-use Possibilities of (Carbonated) Steel Slag}

Environmentally sound re-use (or disposal) of the carbonated products seems essential for further process development of mineral carbonation for $\mathrm{CO}_{2}$ sequestration. In addition, beneficial re-use of the products might reduce $\mathrm{CO}_{2}$ sequestration costs. In order to assess the effect of carbonation on the re-use possibilities of the steel slag in construction, the $\mathrm{pH}_{\text {stat }}$ leaching curves of the fresh and carbonated steel slag samples were compared to the regulatory limits set by the Dutch building materials decree (category 1, application height $1 \mathrm{~m})(S 1)$ (Figure S4). Since the regulatory limits used only apply to the Dutch context, their use and implications should be regarded as an example.

For the fresh steel slag sample $0-\mathrm{c}(<2 \mathrm{~mm})$, the concentrations in the leachates of the majority of elements are orders of magnitude below their limit at native $\mathrm{pH}$, while none of the elements analyzed exceeds its limit at this $\mathrm{pH}^{1}$. The only critical elements are $\mathrm{Ba}$ and $\mathrm{Mo}$, i.e., their concentration in the leachate at the sample's native $\mathrm{pH}$ is below but close to the corresponding regulatory limit. During carbonation, the native $\mathrm{pH}$ of steel slag decreases (2). Possible effects of carbonation can be predicted from the $\mathrm{pH}_{\text {stat }}$ leaching curves of the fresh steel slag sample based on the expected native $\mathrm{pH}$ (i.e., $\mathrm{pH}=8$-12) neglecting other meanwhile occurring processes, such as mineral neoformation and sorption. At $\mathrm{pH}=10$, the $\mathrm{Ba}$ concentration in the leachates could potentially increase to levels above its regulatory limit. Sulfur may become critical if the native $\mathrm{pH}$ decreases towards 8 and $\mathrm{V}$ may already exceed its regulatory limit at only a slightly lower $\mathrm{pH}$. Therefore, from a reuse point of view, $\mathrm{Ba}, \mathrm{S}, \mathrm{V}$ and $\mathrm{Mo}$ are taken into account specifically in the discussion following.

Grinding the fresh steel slag does not form a barrier for the re-use of steel slag from an environmental quality point of view. Of the elements that show increased leaching after grinding, $\mathrm{Cr}, \mathrm{Mn}$ and $\mathrm{Pb}$ do not show altered leaching at either the native $\mathrm{pH}$ of the fresh steel slag or $\mathrm{pH}$-values that can potentially be reached after carbonation ( $\mathrm{pH}=8-12)$. Only Co and $\mathrm{W}$ show increased leaching after grinding over the entire pH-range, but no regulatory limits are exceeded. Prior leaching during the

\footnotetext{
${ }^{1}$ Please note that not all elements for which a regulatory limit exists have been analyzed (viz. $\mathrm{Br}, \mathrm{CN}$, $\mathrm{F}, \mathrm{Hg}, \mathrm{Sb}, \mathrm{Se})$.
} 
aqueous steel slag carbonation process has a beneficial effect on the environmental quality of the carbonated products, i.e. the potentially leachable amounts of e.g. $\mathrm{Cl}, \mathrm{S}$ and Mo are reduced. Finally, carbonation itself reduces the leaching of (regulated) elements due to mineral neoformation (e.g., $\mathrm{Ba}, \mathrm{Ca}, \mathrm{Sr}$ ), $\mathrm{pH}$ reduction (e.g., Al, Fe, $\mathrm{Zn}$ ) and increased sorption at $\mathrm{Al}$ - and Fe-(hydr)oxides of trace elements (e.g., Co).

After carbonation, the concentrations of almost all elements analyzed in the leachates of the carbonated steel slag samples are orders of magnitude below their limit at native $\mathrm{pH}$. However, due to the dissolution of the Ca-vanadate phase upon the $\mathrm{pH}$ decrease and the subsequent carbonation of the $\mathrm{Ca}$ in the autoclave reactor, $\mathrm{V}$ is no longer solubility-controlled by Ca-vanadate and the leaching of $\mathrm{V}$ is enhanced such that its regulatory limit is significantly exceeded at native $\mathrm{pH}$. This observation implies that the carbonated steel slag samples cannot be used directly for construction purposes within the Dutch context. A possible solution could be the application of the carbonated products as filler in concrete, which might reduce the leaching of oxyanions, such as vanadium, due to immobilization as alkaline Ca-phases. Further research on leaching and other aspects of specific re-use applications of carbonated products (e.g., civil engineering demands and possible value) is required for further process development of mineral $\mathrm{CO}_{2}$ sequestration.

\section{Literature Cited}

S1. Bouwstoffenbesluit bodem- en oppervlaktewaterenbescherming (Dutch building material decree) in Staatsblad van het Koninkrijk der Nederlanden (Official Journal of the Kingdom of The Netherlands) (in Dutch), 1995; No 567. 


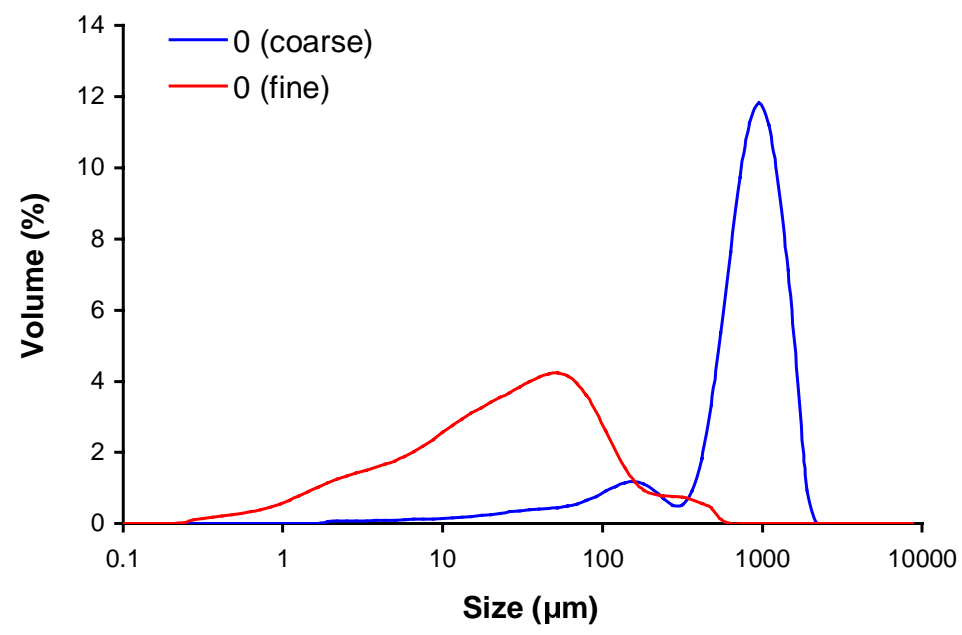

\begin{tabular}{c|cc}
\hline Sample & $d_{0.5}$ & $D[4,3]$ \\
\hline $\begin{array}{c}0-c \\
\text { (coarse) } \\
0-f \\
\text { (fine) }\end{array}$ & 895 & 888 \\
\hline
\end{tabular}

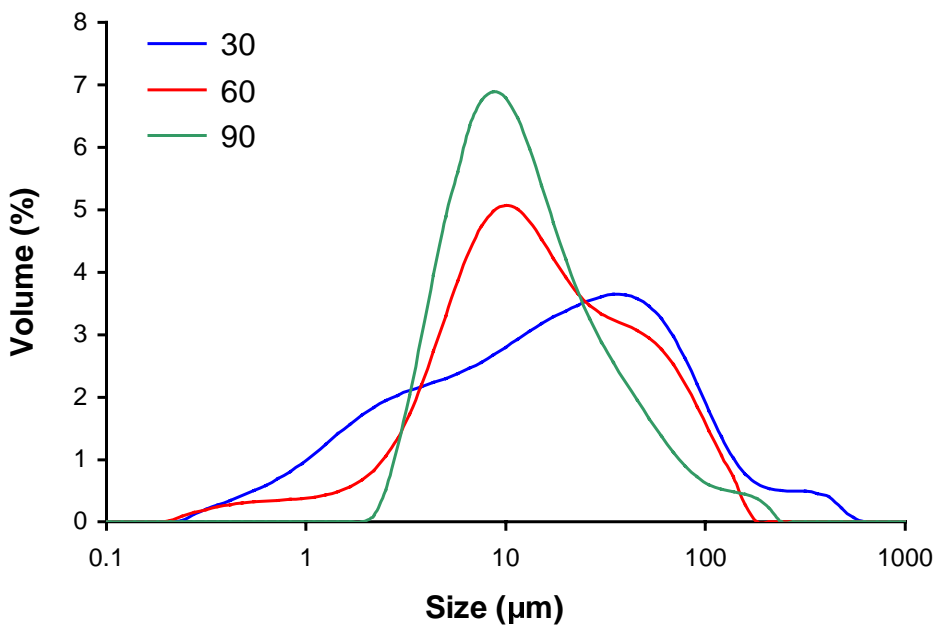

\begin{tabular}{c|cc}
\hline Sample & $d_{0.5}$ & $D[4,3]$ \\
\hline 30 & 18 & 41 \\
60 & 14 & 27 \\
90 & 12 & 22 \\
\hline
\end{tabular}

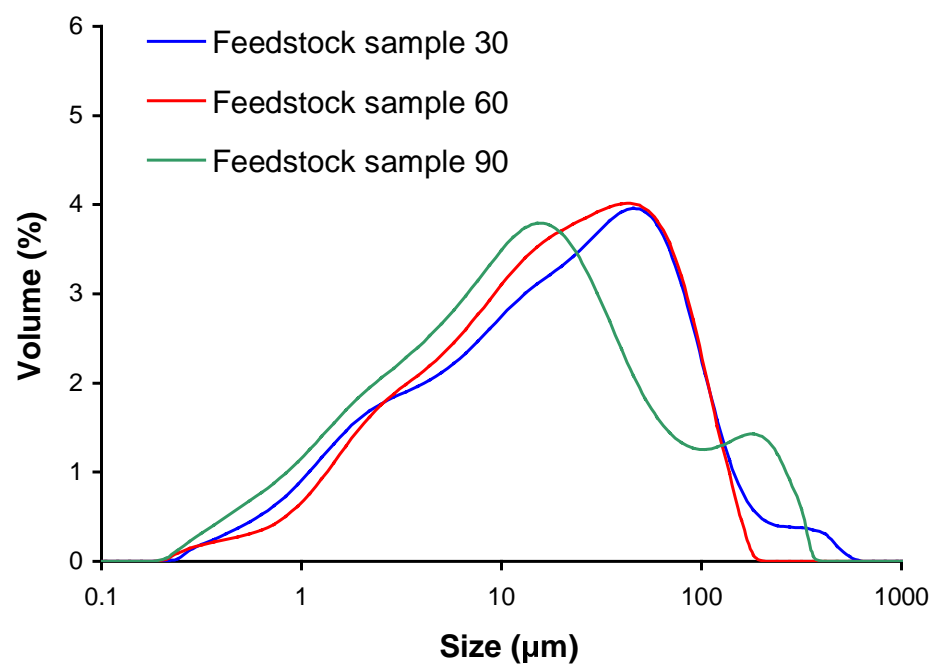

\begin{tabular}{c|cc}
\hline $\begin{array}{c}\text { Feedstock } \\
\text { sample }\end{array}$ & $d_{0.5}$ & $D[4,3]$ \\
\hline 30 & 18 & 37 \\
60 & 20 & 33 \\
90 & 13 & 38 \\
\hline
\end{tabular}

Figure S1. Particle size distribution measured by laser diffraction (suspensions in ethanol, not vibrated) of fresh (top) and carbonated (middle) $\mathrm{pH}_{\text {stat }}$ steel slag samples and of starting material used for the carbonation experiments (bottom). All sizes are given in $\mu \mathrm{m} . \mathrm{d}_{0.5}=$ number-based mean particle size. $\mathrm{D}[4,3]=$ volume-based mean particle size. 

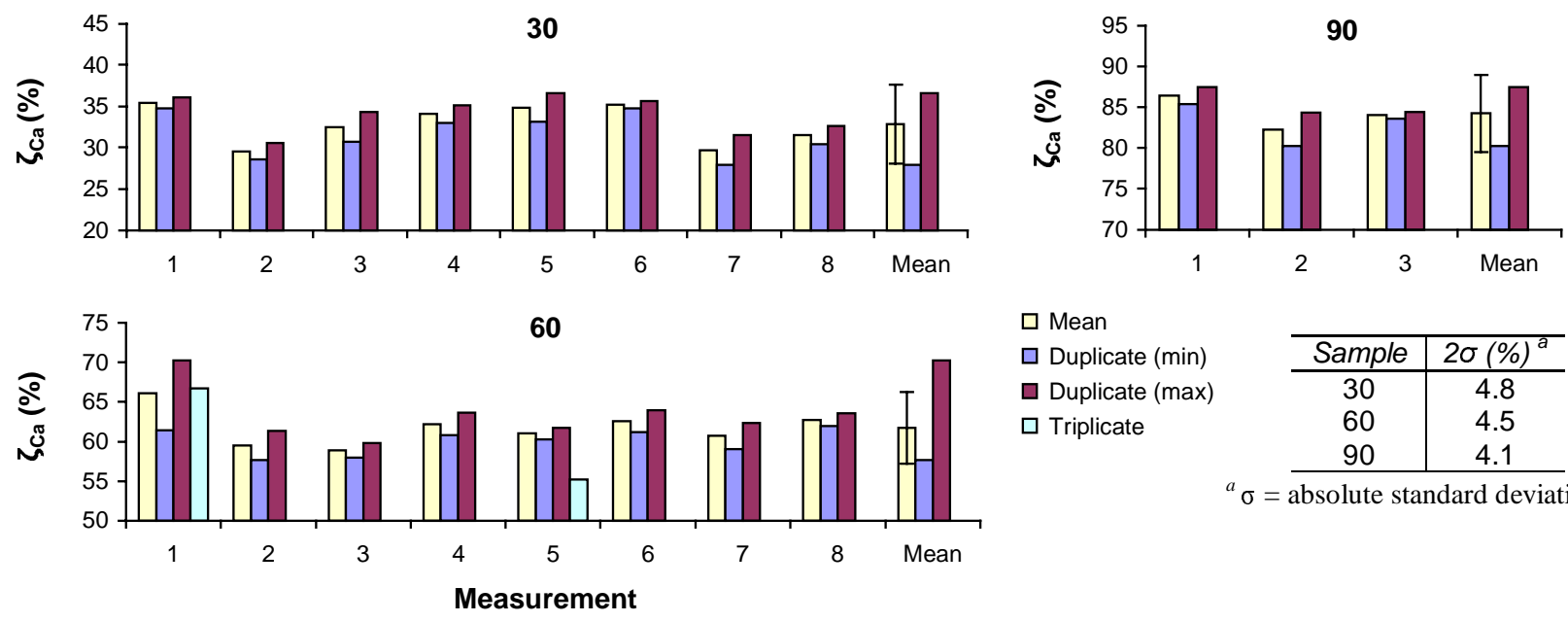

$\square$ Mean

$\square$ Duplicate (min)

$\square$ Duplicate (max)

$\square$ Triplicate

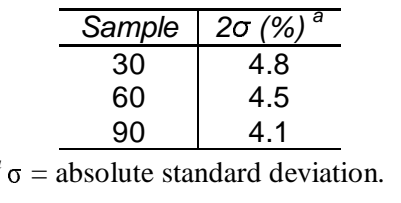

Figure S2. Experimental accuracy of carbonation degree measured $\left(\zeta_{\mathrm{Ca}}\right)$ based on repetition of experiments at identical conditions for preparing $\mathrm{pH}_{\text {stat }}$ samples 30, 60 and 90 . The carbonate content of carbonated products was analyzed at least twice by TGA-MS. If the difference in conversion between the two analyses was larger than $2 \%$., a third analysis was performed and with the help of Grubb's test potential outliers were excluded. 


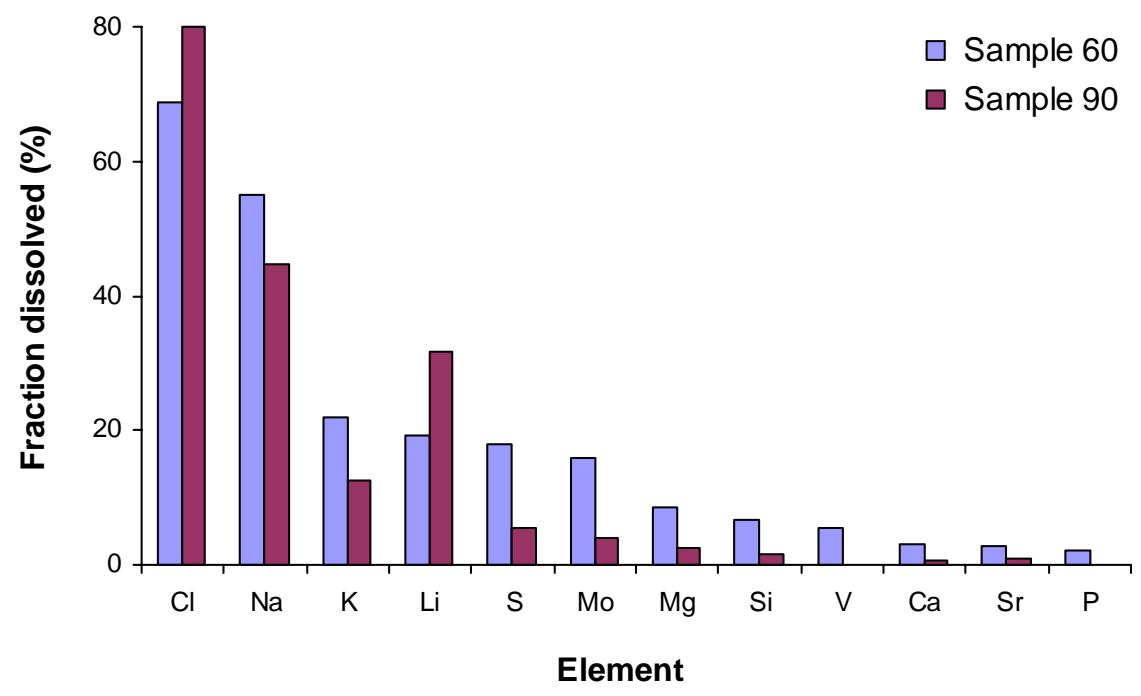

Figure S3. Fraction of the element's total amount present in the fresh steel slag that has dissolved into the process water during preparation of samples 60 and 90 in the autoclave reactor. Elements with fraction $>1 \%$ are shown. 

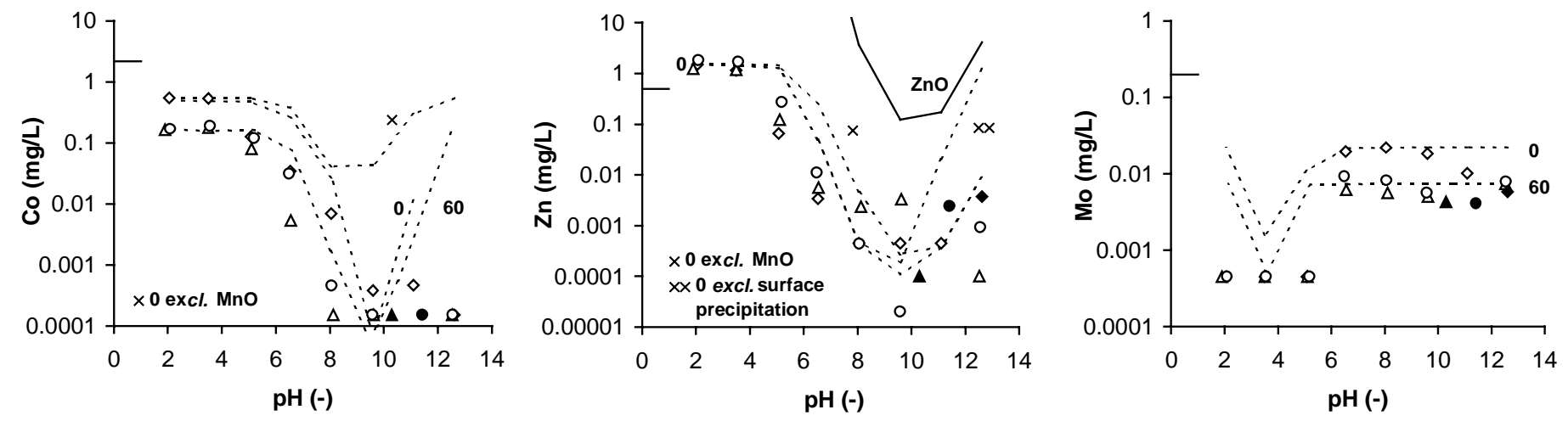

Figure S4. $\mathrm{pH}_{\text {stat }}$ leaching of selected trace elements for the fresh steel slag sample 0-f $(\diamond)$ and carbonated samples $30(O)$ and $60(\Delta)$. Solid symbol: concentration in $\mathrm{pH}_{\text {stat }}$ leachate at native $\mathrm{pH}$. Data points below the detection limit (DTL) are shown as half of the DTL. Selected modeling results for the $\mathrm{pH}_{\text {stat }}$ leachates of samples 0 and 60; either on the basis of solubility control by a specific mineral (- ) or on sorption processes (---.). Short horizontal lines represent the total amount present in the fresh steel slag. 

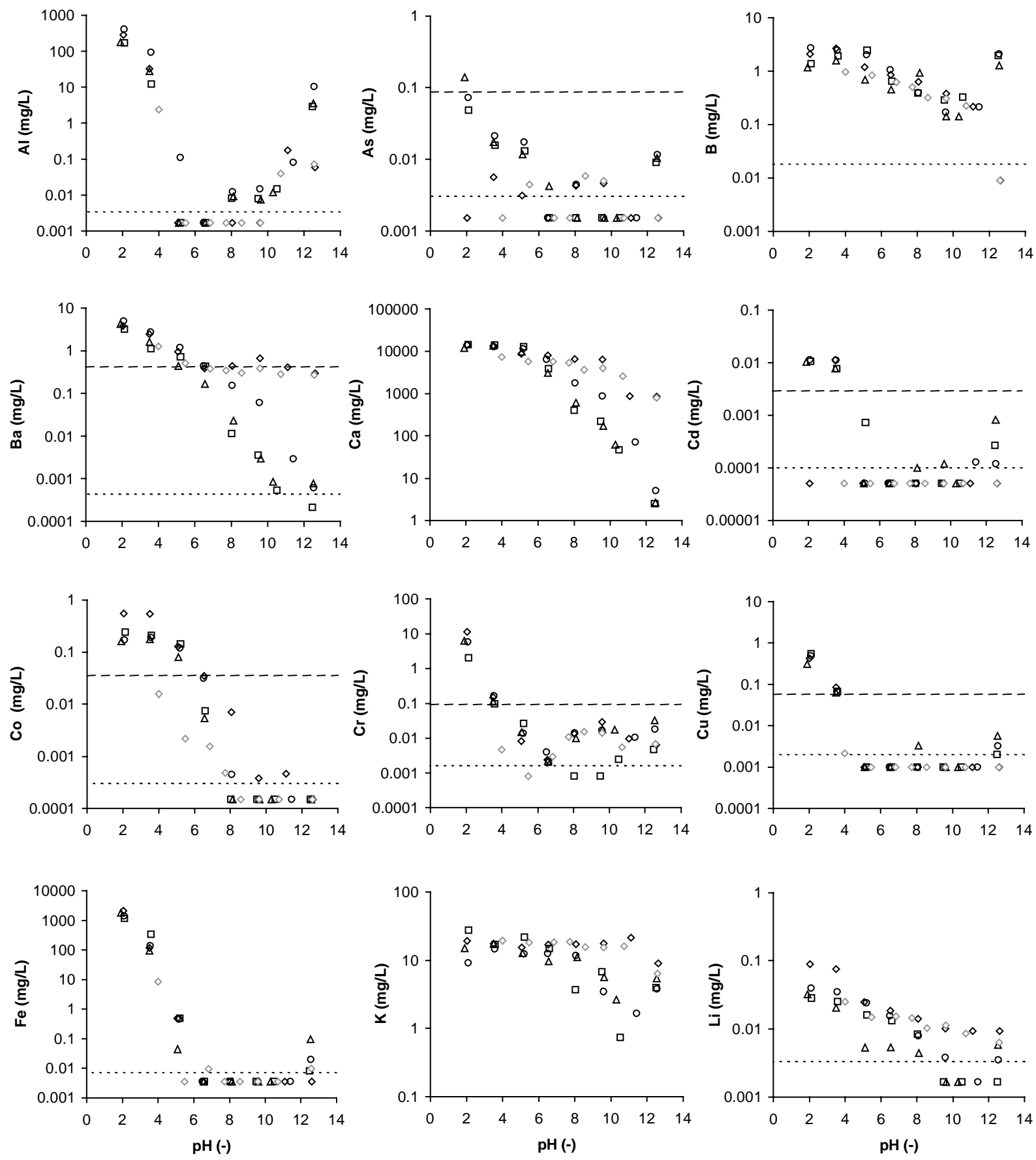

Figure S5. $\mathrm{pH}_{\text {stat }}$ leaching curves of all elements analyzed (except Na), DIC and DOC from the fresh steel slag samples 0-c $(\diamond)$ and 0 -f $(\diamond)$ and carbonated samples $30(O)$, $60(\triangle)$ and $90(\square)$.-- : limit set by the Dutch building materials decree (S1) and ---- : detection limit (DTL). Na-data are not shown since $\mathrm{NaOH}$ is used as base in the $\mathrm{pH}_{\text {stat }}$ leaching tests. Data below the DTL are shown as half of the DTL. 

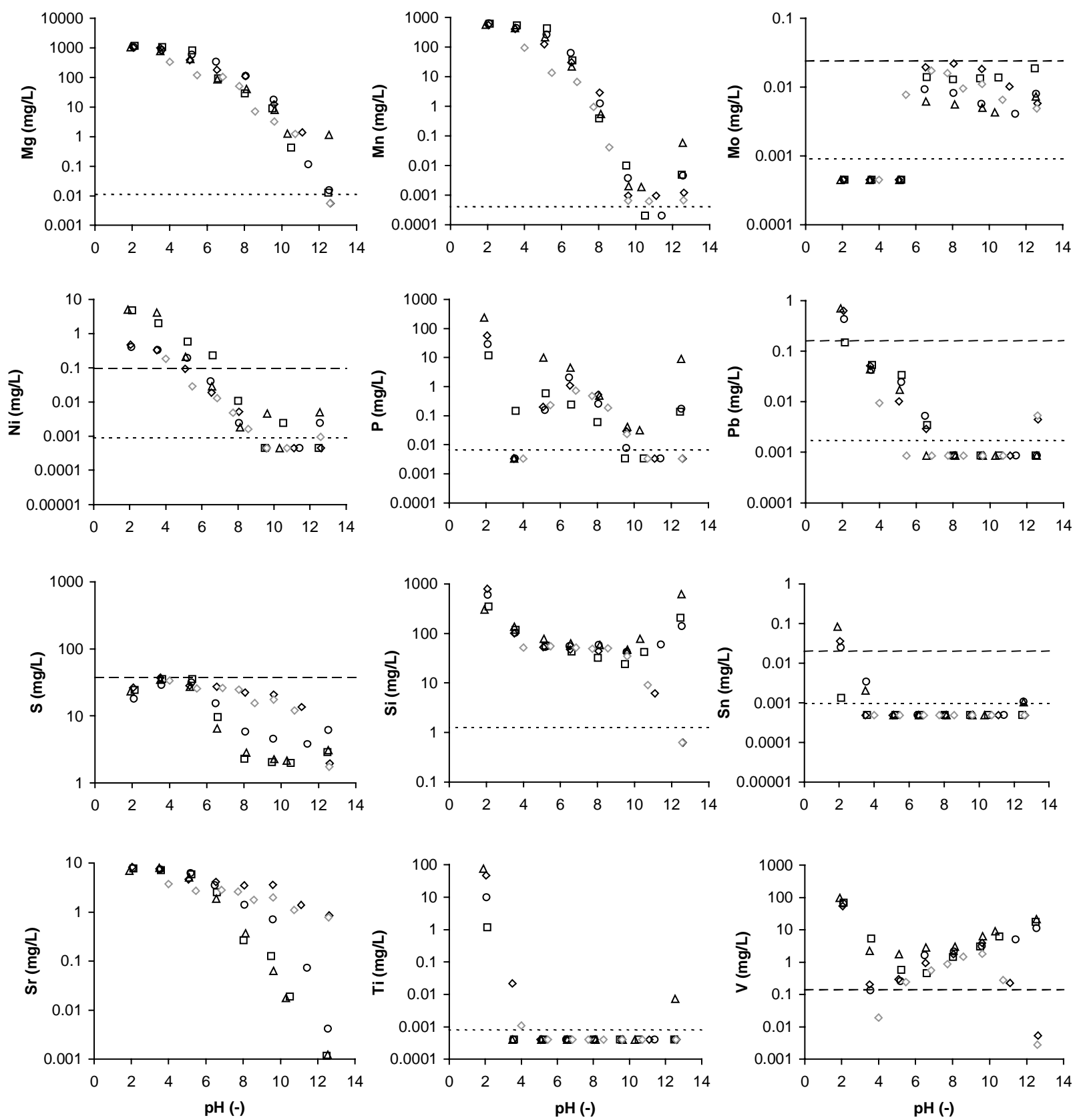

Figure S5. Continued. 

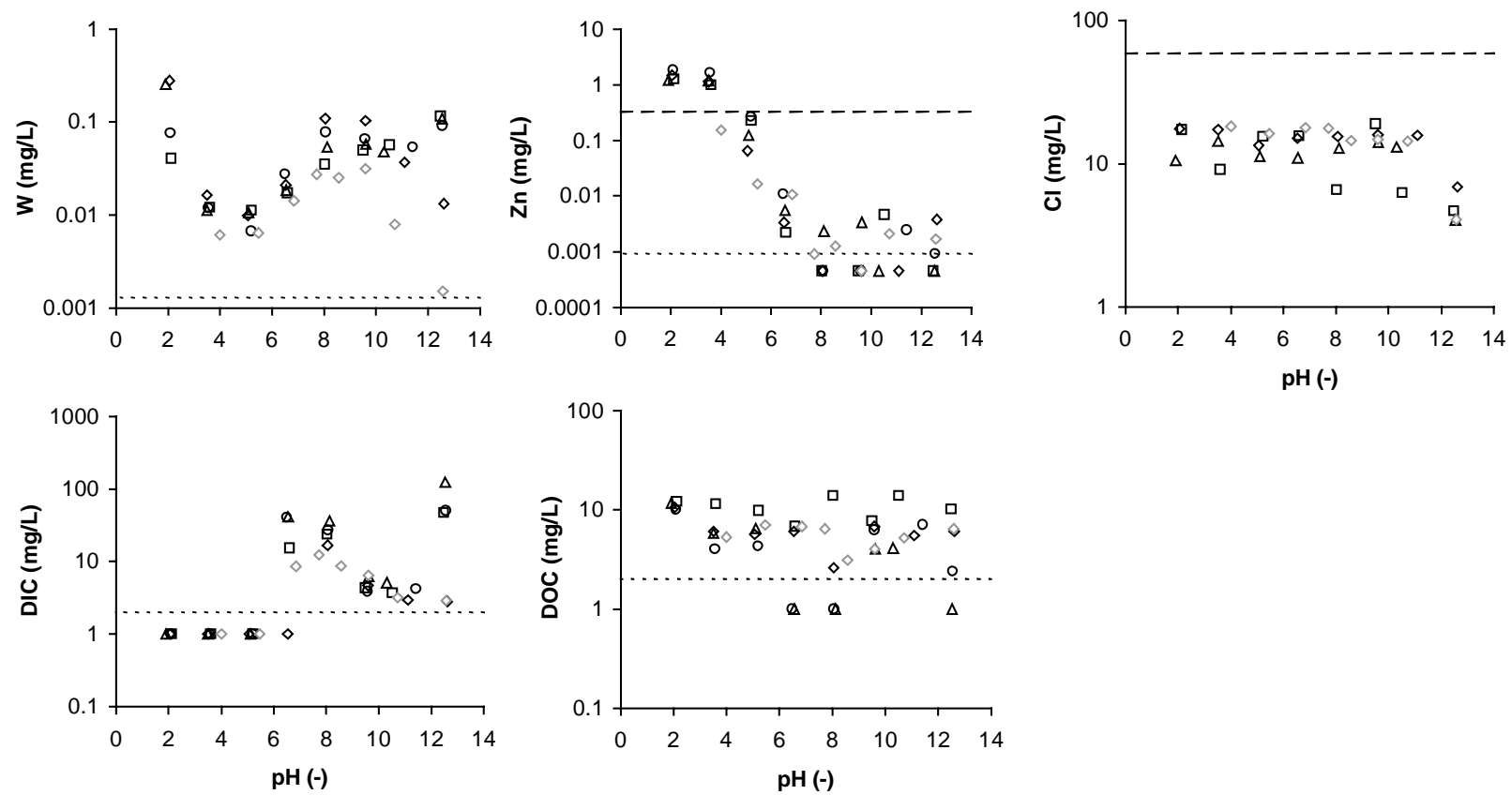

Figure S5. Continued. 